\title{
Preventing Foodborne and Non-foodborne Illness: Vibrio vulnificus $^{1}$
}

Anita C. Wright, Renée Goodrich Schneider, Michael A. Hubbard, and Keith R. Schneider ${ }^{2}$

\section{What is Vibrio vulnificus?}

Vibrio vulnificus occurs naturally in warm brackish and salt water environments. During the warmer months, this bacterium can reach particularly high concentrations in filter-feeding shellfish that inhabit coastal waters. Foodborne illness from $V$. vulnificus is almost exclusively associated with consumption of raw oysters. Properly cooking the shellfish can totally eliminate the risk. Although most cases are likely underreported and unrecognized, infection from $V$. vulnificus is still quite rare. Data from the Food and Drug Administration (FDA) indicated the average occurrence of $V$. vulnificus infection was less than 30 cases per year between 2002 and 2007, and these were due to consumption of raw oysters.

\section{What type of illness can $V$. vulnificus cause?}

Ingesting $V$. vulnificus may occasionally cause abdominal pain, vomiting, and diarrhea among those in good health, but in general exposure of healthy individuals to this bacterium causes no symptoms. However, people with underlying liver disease, hemochromatosis (iron overload), diabetes, or conditions affecting the immune system, such as AIDS, are at higher risk for life-threatening complications that could quickly become fatal-symptoms include fever, chills, and an extreme decrease in blood pressure (septic shock), all due to bacteria multiplying rapidly in the bloodstream. Blistering skin lesions are also diagnostic of this disease. Close to $50 \%$ of these cases have been fatal, and some within 24 hours of the consumption of associated shellfish.

V. vulnificus can also cause illness by infection through open wounds. The bacterium can enter an open wound or skin abrasion through contact with warm seawater, or while handling or shucking raw oysters. The resulting wound infection causes breakdown of skin tissue and possible ulceration. These wound infections can also lead to infection of the blood, known as septicemia, particularly in those who have immune system disorders or liver disease as described above. Thus, persons at higher risk for oyster-related foodborne disease are also the most susceptible to wound infections from $V$. vulnificus that could have fatal consequences. The fatality rate for immunosuppressed patients presenting with $V$.

1. This document is FSHN09-02, one of a series of the Food Science and Human Nutrition Department, Florida Cooperative Extension Service, Institute of Food and Agricultural Sciences, University of Florida. Original publication date July 2009. Visit the EDIS Web site at http://edis.ifas.ufl.edu.

2. Anita C. Wright, associate professor; Renée Goodrich Schneider, associate professor; Michael A. Hubbard, lab technician; Keith R. Schneider, associate professor; Department of Food Science and Human Nutrition; Institute of Food and Agricultural Sciences; University of Florida; Gainesville 32611.

The Institute of Food and Agricultural Sciences (IFAS) is an Equal Opportunity Institution authorized to provide research, educational information and other services only to individuals and institutions that function with non-discrimination with respect to race, creed, color, religion, age, disability, sex, sexual orientation, marital status, national origin, political opinions or affiliations. U.S. Department of Agriculture, Cooperative Extension Service, University of Florida, IFAS, Florida A. \& M. University Cooperative Extension Program, and Boards of County Commissioners Cooperating. Millie Ferrer-Chancy, Interim Dean 
vulnificus wound infections is about 20 percent, according to the Centers for Disease Control and Prevention (CDC).

\section{What activities can cause illness related to Vibrio vulnificus?}

Eating raw oysters or lightly cooked seafood, or exposing an open wound to seawater harboring $V$. vulnificus can result in infections. The bacterium is often isolated from oysters and other shellfish as well as from their habitats during the summer months in warm, coastal waters. There is no evidence, however, of person-to-person transmission.

\section{What foods have been most commonly associated with Vibrio vulnificus and why?}

The food most commonly associated with $V$. vulnificus is raw oysters. Contamination does not affect qualities of the oyster such as odor, taste, or appearance, but Vibrio vulnificus can still be present in high concentrations. Unlike many other human pathogens, the presence of $V$. vulnificus is not linked with presence of fecal material that may contaminate recreational waters through human or agricultural wastes. $V$. vulnificus is a natural inhabitant of seawater environments and can be recovered throughout the year from sediment, water, and marine life samples, but its numbers greatly increase in the warmer months, as does the number of reported illnesses associated with this organism. Thus, persons at risk for this disease should be particularly cautious to avoid exposure to uncooked seafood or exposure of wounds during summer months.

Other seafood, particularly other shellfish such as clams, can also become a potential hazard if they are not properly stored and prepared, and fish that eat oysters may have high levels of this bacterium in their digestive tracts. Cooking oysters through steaming, baking, or frying will readily destroy this organism. Individuals that are in any of the high-risk groups should thoroughly cook oysters and other potentially contaminated seafood, and take the utmost precautions in handling (or altogether avoid) these products.

\section{What are the diagnostic signs and symptoms associated with Vibrio vulnificus?}

Illness due to $V$. vulnificus is often diagnosed with symptoms of fever, gastrointestinal illness, or septic shock after consumption of contaminated food or exposure of an open wound to seawater or marine life. Skin lesions resembling blisters may also appear on the arms and legs as the disease progresses.

Diagnosis of this illness can be done through testing blood, wound cultures, or stool samples for presence of the organism. A Vibrio-specific growth medium is used to culture the organism and confirm the diagnosis.

\section{Who is at risk and why?}

People with previous medical conditions can acquire $V$. vulnificus disease from eating raw seafood, especially oysters. Those persons with either immune system disorders (such as AIDS) or on immunosuppressive medication, chronic liver disease, hemochromatosis (iron overload disease), and/or insulin-dependent diabetes are at the greatest risk for infection and should avoid raw seafood products. Even though foodborne illness associated with $V$. vulnificus is rare, fatality rates of immunosuppressed patients infected by $V$. vulnificus can approach $60 \%$. Persons with these preexisting medical conditions, or persons who are very young or elderly, should also avoid exposure to seawater/brackish water.

\section{Receiving and storage of seafood and shellfish}

Specific recommendations from the FDA's 2005 Food Code for handling and storage of seafood and shellfish in a retail or food service operation are available at http://www.cfsan.fda.gov/ dms/fc05-toc.html. Seafood and shellfish are considered Potentially Hazardous Foods because foodborne pathogens increase in number if temperature abuse occurs. Most foods in this category should be kept at either above $135^{\circ} \mathrm{F}$ (after cooking) or below $41^{\circ} \mathrm{F}$ (storage), with temperatures in the middle being considered 
part of the "danger zone." As a rule of thumb, foods should spend no more than 4 hours in the "danger zone" temperature range. Shellfish are an exception and should be transported and received at $45^{\circ} \mathrm{F}$.

Once a product is frozen, it is important to maintain a proper freezer temperature to avoid product thawing. Labeling properly stored foods is also helpful to ensure that others handling the food in the future will know exactly how long a food product has been stored.

Seafood in interstate commerce must be produced under the Seafood HACCP regulation. Detailed information can be found on the FDA Web site (http://www.cfsan.fda.gov). For Florida-specific requirements, please see the Florida Department of Agriculture and Consumer Services Web pages (http://doacs.state.fl.us).

\section{Methods to help prevent infection by Vibrio vulnificus in individuals who are in high-risk groups}

These suggestions should always be followed to help prevent infection, especially for persons with underlying diseases that place them in high-risk groups.

- Do not eat raw shellfish, especially oysters if you are immunocompromised or have hemochromatosis or diabetes.

- Cook shellfish thoroughly.

For shellfish still in the shell

1. Steam until the shell opens and continue to cook for at least 9 more minutes. Do not eat if shell does not open during steaming.

2. Boil until the shell opens and continue to cook for 5 minutes.

For shucked oysters

1. Boil for at least 3 minutes.

2. Fry in oil at $375^{\circ} \mathrm{F}$ for at least 10 minutes.

- Avoid cross-contamination of other cooked foods with raw seafood or juices from raw seafood. Disinfect all surfaces, cutting boards, and utensils properly.
- When in coastal areas, avoid exposing skin abrasions or wounds to seawater/brackish water or raw seafood.

\section{References}

Centers for Disease Control and Prevention (CDC), Division of Bacterial and Mycotic Diseases. Vibrio vulnificus. Retrieved March 30, 2009 from http://www.cdc.gov/nczved/dfbmd/disease_listing/ vibriov_gi.html.

Centers for Disease Control and Prevention, Division of Emergency Preparedness and Response. 2005.

Vibrio vulnificus After a Disaster. Retrieved July 29, 2009 from

http://www.bt.cdc.gov/disasters/vibriovulnificus.asp.

US Department of Health and Human Services. 2005 FDA Food Code. Retrieved March 30, 2009 from http://www.cfsan.fda.gov/ dms/fc05-toc.html.

Clemson Extension. Home and Garden Information Center. Last date of access: 30 March 2009. http://hgic.clemson.edu.

Jones, M.K. and J.D. Oliver. 2009. Vibrio vulnificus: Disease and Pathogenesis. Infect. Immun. doi:10.1128/IAI.01046-08. 